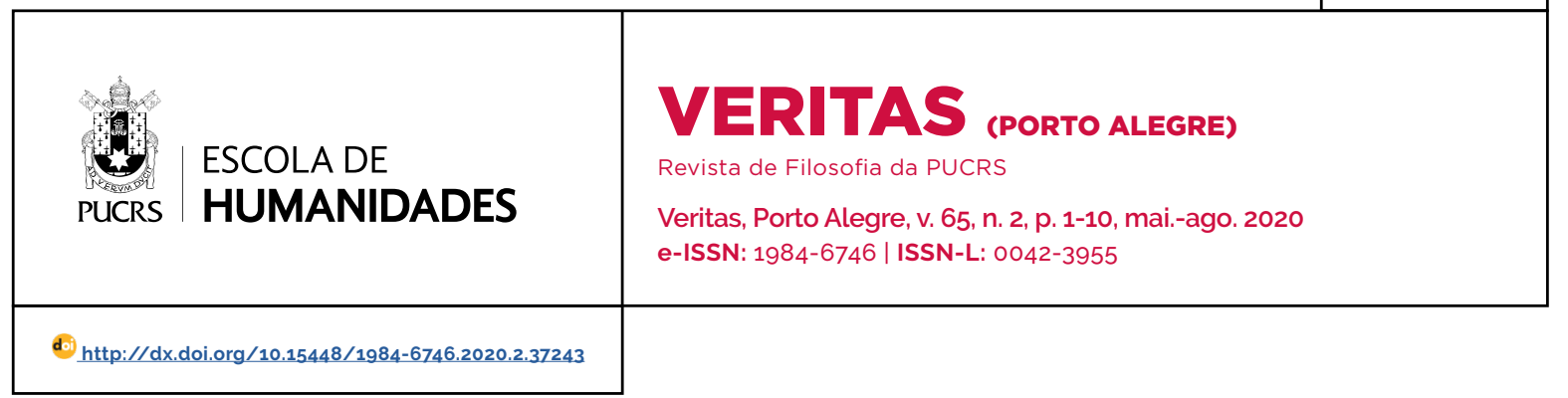

SEÇÃO: ESTÉTICA

\title{
Gadamer e a experiência hermenêutica da arquitetura
}

Gadamer and the hermeneutical experience of architecture

Gadamer e la experiencia hermenéutica de la arquitectura

\section{Gustavo Silvano \\ Batista $^{1}$}

orcid.org/0000-0002-9399-2541 silvanobatista@gmail.com

Recebido em: 1 mar. 2020. Aprovado em: 27 abr. 2020. Publicado em: 28 jul. 2020.

\section{(c) (i)}

Artigo está licenciado sob forma de uma licença Creative Commons Atribuição 4.0 Internacional.
Resumo: Na abordagem hermenêutica das obras de arte, Gadamer discute a arquitetura como uma das expressões artísticas na qual se pode reconsiderar a relação ontológico-interpretativa com as coisas em geral. Repensando a estrutura representativa própria da experiência hermenêutica das obras de arte, Gadamer introduz a arquitetura como uma expressão artística peculiar, na qual as obras de arte resistem aos posicionamentos estéticos atuais, reinserindo-as na esfera prática da vida. Essa tematização encontra ecos importantes na teoria e prática arquitetônicas, à medida que possibilita uma nova relação com as obras de arquitetura, para além das variáveis estéticas. O presente artigo, portanto, tem como objetivo discutir a experiência hermenêutica da arquitetura como um momento interpretativo decisivo da relação com as obras de arte, explicitando tanto o caráter ontológico-hermenêutico do pensamento de Gadamer quanto o traço hermenêutico das obras de arquitetura. Para isso, partimos de um diálogo estabelecido por Gadamer e dois arquitetos, Jacques Herzog e Pierre de Meuron, sobre a essência da arquitetura. A resposta gadameriana indicou-nos o horizonte de tematização das obras arquitetônicas como extensão da experiência da obra de arte, tal como foi discutido em Verdade e Método, notadamente na discussão sobre a representação artística e a retomada das noções de ocasional e decorativo. A tematização hermenêutica encontra, por conseguinte, repercussões na teoria e prática arquitetônicas, indicando um horizonte alternativo de questionamento do sentido da arquitetura e urbanismo, situando-o e remetendo-o para o horizonte da vida em comum.

Palavras-chave: Gadamer. Arte. Ontologia. Arquitetura. Representação. Compreensão.

Abstract: In the hermeneutical reflection of the artworks, Gadamer discusses architecture as one of the artistic expressions where one can reconsider the ontological-interpretative relationship with things in general. Rethinking the representative structure of the hermeneutic experience of works of art, Gadamer introduces architecture as a peculiar artistic expression, which works of art resist current aesthetic positions, reinserting them in the practical sphere of life. This topic finds important echoes in architectural theory and practice, as it enables a new relationship with works of architecture, beyond from the aesthetic variables. The present article aims to discuss the hermeneutic experience of architecture as a decisive interpretive moment of the relationship with works of art, explaining the ontological-hermeneutic character of Gadamer's thought and the hermeneutic trace of works of architecture. For that, we were beginning from a dialogue established by Gadamer and two architects, Jacques Herzog and Pierre de Meuron, about the essence of architecture. The gadamerian answer showed us the horizon of thematization of architectural works as an extension of the experience of the work of art, as was discussed in Truth and Method, notably in the discussion about artistic representation and rehabilitation of the occasional and decorative. Hermeneutic thematization consequently finds repercussions in architectural theory and practice, indicating an alternative horizon of questioning of the meaning of architecture and urbanism, placing it and referring it in the horizon of life in common. Keywords: Gadamer. Art. Ontology. Architecture. Representation. Understanding.

Resumen: En la reflexión hermenéutica de las obras de arte, Gadamer analiza la arquitectura como una de las expresiones artísticas en las que se puede 
reconsiderar la relación ontológica-interpretativa con las cosas en general. Al repensar la estructura representativa típica de la experiencia hermenéutica de las obras de arte, Gadamer presenta la arquitectura como una expresión artística peculiar, en la que las obras de arte resisten las posiciones estéticas actuales, reinsertándolas en la esfera práctica de la vida. Este tema encuentra ecos importantes en la teoria y práctica arquitectónica, ya que permite una nueva relación con las obras de arquitectura, además de las variables estéticas. El presente artículo tiene como objetivo discutir la experiencia hermenéutica de la arquitectura como un momento interpretativo decisivo de la relación con las obras de arte, explicando tanto el carácter ontológico-hermenéutico del pensamiento de Gadamer como el rasgo hermenéutico de las obras de arquitectura. Para esto, partimos de un diálogo establecido por Gadamer y dos arquitectos, Jacques Herzog y Pierre de Meuron sobre la esencia de la arquitectura. La respuesta gadameriana nos mostró el horizonte de la tematización de las obras arquitectónicas como una extensión de la experiencia de la obra de arte, como se discutió en Verdad y Método, especialmente en la discusión sobre la representación artística y la reanudación de las nociones de lo ocasional y lo decorativo. La tematización hermenéutica, por lo tanto, tiene repercusiones en la teoría y práctica arquitectónica, indicando un horizonte alternativo para cuestionar el significado de la arquitectura y el urbanismo, ubicándolo y refiriéndolo al horizonte de la vida en común.

Palabras clave: Gadamer. Arte. Ontología. Arquitectura. Representación. Comprensión.

\section{Introdução}

A reflexão acerca da arquitetura como uma questão hermenêutica sempre teve um papel secundário na obra de Hans-Georg Gadamer. Contudo, o tema aparece em diversos momentos, seja em conferências ou entrevistas, ou ainda em artigos publicados durante sua segunda juventude. ${ }^{2}$ Nessas diversas ocasiões nas quais o filósofo de Heidelberg tratou do assunto, sempre estava em jogo a elucidação de caráter fundamental da arquitetura no cerne do posicionamento hermenêutico acerca das obras de arte em geral, assim como a repercussão das obras arquitetônicas nas artes em geral, à medida que, enquanto edificação ou ainda projeto, ressignificam o espaço vivido no qual estão inseridas.

Notadamente em uma ocasião, quando Gadamer já se encontrava com 96 anos, os arquitetos Jacques Herzog e Pierre de Meuron³ convida- ram-no para participar de um projeto do Centro George Pompidou, que se tornaria posteriormente uma exposição sobre a relação atual da arquitetura com os novos meios de comunicação. Esse projeto tratava-se da reunião de entrevistas com individuos de áreas e gerações diferentes, ou seja, um adolescente, um psicólogo, um filósofo, entre outros, indagando-os com a pergunta o que é arquitetura? que pudessem compor uma exposição.

Mesmo com a não realização da exposição, por falta de financiamento, os arquitetos realizaram uma das entrevistas com Gadamer. Naquela ocasião, a pergunta-chave (o que é arquitetura?) conduziu a reflexão que Gadamer concedeu como resposta, ressaltando a experiência da arquitetura como um elemento importante não somente para seu pensamento, mas para a experiência comunitária e cotidiana da efetividade da vida. Desta forma, Gadamer apontou como uma experiência arquitetônica fundamental uma memória de infância, ou seja, a sua relação com um ambiente da casa de seus pais: a sala de recepções que se destacava pelo seu assoalho de madeira parquet cuidadosamente encerado, frequentada por ocasião de visitas e em alguns momentos festivos do ano. Relata-nos Herzog:

Gadamer falou de uma superfície mágica - um
piso de madeira maravilhoso, tão bem conserva-
do e polido que todo o espaço era tomado pelo
odor da cera. De vez em quando um amigo do
seu pai os visitava [... e, ao adentrar a sala proibi-
da, sempre deixava seu casaco e guarda-chuva,
que molhavam o piso mágico. Como criança,
Hans-Georg ficava horrorizado com tal gesto do
amigo do seu pai. Ele ainda se lembra de modo
muito vivo a imagem do piso de madeira polido
decorado com as gotas de água do guarda-chu-
va encharcado (HERZOG, 2001, p. 115).

Tal lembrança, de um ambiente construido e modelado artesanalmente por um assoalho de madeira maciça, indicava um sentido próprio que Gadamer remete à arquitetura em geral, compreendido como uma experiência hermenêutica decisiva nos recintos projetados e edi-

\footnotetext{
2 Termo utilizado por Jean Grondin para se referir ao periodo de aposentadoria de Gadamer, momento no qual o filósofo divide seu tempo entre Heidelberg e a América do Norte. GRONDIN, J. Hans-Georg Gadamer: a biography. New Haven: Yale University Press. p. 313. 3 Jacques Herzog e Pierre de Meuron, arquitetos suiços, são sócios na Herzog \& de Meuron Architekten, sediada em Basiléia, Suiça, desde 1978. São muito conhecidos por terem transformado a Central Elétrica Bankside, na cidade de Londres, na nova sede do museu Tate Modern, no ano 2000. Ambos receberam o Pritzker Prize em 2001.
} 
ficados. Jacques Herzog nomeou tal episódio de Gadamer's floor, ${ }^{4}$ à medida que tal reflexão ilumina não somente as próprias considerações de Gadamer sobre a arquitetura em geral, mas a própria atividade arquitetônica contemporânea, tendo em vista os atuais desafios com os quais se deparam os que se dedicam à arquitetura.

Esse episódio situa-se, a nosso ver, na perspectiva de uma reivindicação de uma experiência da arquitetura, no cerne da reflexão sobre a experiência hermenêutica (Erfahrung) da obra de arte, na tentativa de localizar a compreensão, questão hermenêutica básica no horizonte da relação com a arte, mais abrangente que a consideração estética clássica das obras de arte. Em outras palavras, Gadamer compreende a necessidade de repensarmos a experiência da obra de arte - e por conseguinte da arquitetura - nos termos de um pensamento ontológico-interpretativo, tendo em vista o momento da compreensão como aquele que faz justiça à esfera da vida prática na qual estão inseridas as próprias obras de arte em geral.

\section{A arquitetura na perspectiva da hermenêutica: da representação artística ao sentido do edifício}

O tratamento teórico-filosófico que Gadamer dá ao tema arquitetônico, vinculando as obras arquitetônicas ao horizonte da reflexão acerca da experiência hermenêutica da obra de arte, oferece desdobramentos importantes tanto para a pesquisa sobre o projeto hermenêutico gadameriano quanto para a teoria da arquitetura e urbanismo ${ }^{5}$. Neste sentido, tanto em Verdade e Método, sua principal obra, quanto em escritos posteriores, 0 tema da arquitetura aparece como um momento de repensar a relação hermenêutica com a arte, tendo em vista a efetividade da vida prática em comum na qual estamos todos inseridos.

Dito de outro modo, pensar a relação com a arquitetura, na perspectiva hermenêutica da experiência da obra de arte, indica um horizonte de reflexão peculiar, que atravessa de modo especifico os projetos e edificações já construídas, tendo em vista uma experiência compreensiva que não perde de vista a esfera da vida em comum, elucidando assim traços hermenêuticos relevantes. Deste modo, o presente artigo pretende discutir os traços hermenêuticos da arquitetura, nos termos de uma experiência (Erfahrung), como um momento no qual o acontecer compreensivo se dá de modo decisivo, contribuindo assim para a visualização do caráter interpretativo da relação entre intérprete e obras de arte e de arquitetura.

Em Verdade e Método, Gadamer dedica-se a apresentar a inteligibilidade da arquitetura, seja em forma de projeto ou obra construída, nas considerações sobre o caráter ontológico das obras de arte. A reivindicação de uma outra relação com arte, para além dos ditames e problematizações estéticos, leva Gadamer a pensar a arquitetura como um dos momentos no qual a experiência hermenêutica especialmente sucede-se. Nas palavras de Paul Kidder,

[...] uma abordagem hermenêutica da arquitetura tem o modelo hermenêutico de pensamento e experiência em diversas áreas do empreendimento arquitetônico. Isso pode ser encontrado tanto na atividade criativa do arquiteto quanto na apreciação estética das criações arquitetônicas (KIDDER, 2013, p. 1).

Assim, na perspectiva de uma hermenêutica da obra de arte, Gadamer também assume como tarefa elucidar o evento compreensivo tal como se desdobra especificamente na arquitetura. Tal complementação indica a necessidade de considerar a arquitetura como um momento que caracteriza de modo decisivo a própria relação com a arte, desdobrando-se em um outro modelo representacional alternativo aos desdobramentos estéticos.

Para Gadamer, a experiência estética, principalmente aquela reivindicada por Kant e desenvolvida por Schiller, retira o objeto artístico de seu contexto vital básico, remetendo a arte a uma esfera de pensamento no qual estão em

\footnotetext{
4 O episódio detalhado da entrevista de Gadamer encontra-se relatado por Jacques Herzog no artigo HERZOG, J. Thinking of Gadamer's floor. In: DAVIDSON, Cynthia C. (Ed.). Anything. New York/ Cambridge: Anyone Corporation/The MIT Press, 2001. p. 114-119.

5 Em 1968, Gadamer teve como aluno o arquiteto Dalibor Vesely, que foi fortemente influenciado pela hermenêutica filosófica. Sua obra Architecture in the age of divided representation é em grande medida resultado de sua relação com Gadamer, na tentativa de repensar o papel contemporâneo da arquitetura.
} 
jogo elementos que a distanciam da própria relação entre vida e obra, tais como a beleza, por exemplo, analisando e qualificando as obras nelas mesmas, deixando para segundo plano o âmbito comum de referências no qual se insere a própria obra. Tal posicionamento, pensado por Gadamer nos termos de uma diferenciação estética, destaca a obra do mundo da vida prática no qual está inserida, deslocando-a muitas vezes para um museu ou galeria de arte, permitindo assim uma relação diferenciada com a própria obra, possibilitando ao sujeito a oportunidade de contemplação artistica distante do mundo da obra. Como nos lembra Dalibor Vesely,

[...] devido à sua natureza subjetiva, a realidade estética é inevitavelmente idêntica à experiência subjetiva. A obra de arte se torna um mundo em si, virtualmente removido de toda conexão com a realidade prática; é para ser experimentado apenas como uma bela forma estética (VESELY, 1985, p. 26).

A perspectiva apontada por Vesely marca a reflexão de Gadamer à medida que se faz necessário repensar a própria relação com a arte nos termos de um modelo alternativo da representação artística, à medida que a relação sujeito/ objeto, em termos metodológicos modernos, destaca a obra da efetividade prática da vida.

Deste modo, na perspectiva de um novo modelo de representação - a partir do qual uma verdade mais primordial é vislumbrada - a arquitetura tem um caráter exemplar. Isto porque, enquanto na estética convencional, os elementos considerados estão basicamente circunscritos à própria obra, na abordagem hermenêutica considera-se a obra em um sentido mais ampliado e situado, levando em conta também as referências presentes na própria obra e sua história, ainda que disponivel em um museu. Nesse sentido, tanto a obra quanto o seu entorno são relevantes para a elucidação hermenêutica de seu sentido. Tal perspectiva, considerada por Gadamer como um traço de não-diferenciação estética indica um papel fundamental para a arquitetura, pois é nela que tal aspecto vital será recuperado.

Em relação às obras arquitetônicas em geral, que em grande medida abrigam diversas obras de arte, Gadamer aponta aspectos importantes a serem considerados. Diante da multiplicidade de obras arquitetônicas que surgiram ao longo da história do Ocidente, desde o templo grego até um edificio contemporâneo projetado por Rem Koolhaas, devem ser examinados, em uma perspectiva hermenêutica, como obras que nos oferece uma nova experiência artística de verdade. Tal experiência, em grande medida marcada por elementos como a mediação entre o passado e o presente, ou ainda pelo vínculo com o lugar onde está edificada, permeia interpretativamente a própria representação destas obras. Tal aspecto é fundamental para Gadamer.

Desta forma, para pensar tal experiência, retornarmos a Verdade e Método, onde Gadamer discorre sobre o tema da arquitetura em meio à discussão sobre a questão da representação na pintura. Nas seções "A valência ontológica da imagem (Bild)" (GADAMER, 2004, p. 130) e "O fundamento ontológico do ocasional e decorativo" (GADAMER, 2004, p. 138), Gadamer dedica-se a esclarecer uma experiência da verdade reivindicada pelo pensamento hermenêutico e estendida à arquitetura, pensando também o modelo de relação com a arte nos termos de uma nova estrutura representativa para o próprio pensamento hermenêutico, considerando a experiência hermenêutica da verdade da arte como exemplar.

Deste modo, ao reabilitar os elementos ontológicos ocasional e decorativo, típicos da relação hermenêutica com a obra de arte, ainda que abandonados pela estética, Gadamer coloca-se na discussão da relação com a arte, notadamente em uma perspectiva espacial, reivindicando para a experiência da arte o vínculo intrínseco - e jamais perdido - com o seu lugar, mesmo que outrora limitado pelo conceito de consciência estética que, na perspectiva de Gadamer, descontextualiza as obras de arte, apartando-as de seu mundo.

Assim, a reabilitação dos conceitos ocasional e decorativo, ou seja, os traços temporal e espacial inerentes a qualquer obra de arte, indica um elemento decisivo para a elucidação da experiência interpretativa da obra de arte, em termos de uma mediação entre obra e contexto da vida enquanto 
uma experiência interpretativa e situada da arte na qual a relação entre intérprete e obra sempre se dá de modo localizado.

No desenvolvimento de uma ontologia de natureza interpretativa, que tem como referência básica a experiência da obra de arte, Gadamer questionou o uso do termo 'imagem' (Bild), assim como tudo que está historicamente ligado a ela. Essa questão busca dissolver os "conceitos ingênuos de imagem e escultura", característicos da arte experiencial, nos quais a obra de arte é marcada por referência àquele sujeito que contempla e considera apenas os critérios próprio na compreensão e análise das obras, tendo como referência um ideal de belo. Gadamer procura examinar o modo de ser da imagem e, por meio dela, esclarecer a estrutura ontológica da relação com as obras de arte, revelando uma estrutura representativa ocasional e decorativa que faz justiça às demandas do compreender.

Considerando os desenvolvimentos contemporâneos da estética, fundamentalmente marcados pela crise da imagem, decorrente das condições modernas da vida industrial e funcionalizada, Gadamer identifica nossa época como aquela em que não temos mais espaço para as obras de arte e, por esse motivo, a falta de lugares para as obras de arte se torna um problema iminente. Do ponto de vista de Gadamer, tais lugares não se limitariam aos museus ou galerias, mas significa um retorno ao mundo da vida comum, ou seja, à totalidade das referências de sentido que emerge da própria obra e ao mesmo tempo a situa, permitindo assim uma ampla difusão de sentidos para além da fruição estética.

Ao tratar particularmente das obras de arquitetura em geral, Gadamer se volta para a discussão da representação na pintura. Um novo tratamento da relação com a imagem, ou seja, considerando o evento da compreensão tal como ocorre na relação com as obras, proporciona a concepção de uma nova estrutura representativa inerente à relação com as mesmas obras, repensando assim a própria relação entre sujeito e objeto.
Assim, a abordagem hermenêutica da arquitetura não poderia ser pensada apartada da discussão sobre a arte e sua estrutura representativa, pois o próprio arcabouço representativo é mais bem compreendido à medida que também é apontado no modo de ser da própria arquitetura, enquanto experiência hermenêutica.

Ao recuperar as noções de ocasional e decorativo, Gadamer repensa a experiência das obras de arte retornando à análise da representação artística, desvinculando-a do modelo subjetivista de representação (pensada como Vorstellung) que, ao seu ver, fundamenta a experiência estética, não mais apropriada a relação hermenêutica com as obras de arte.

Neste sentido, segundo Gadamer, a concepção convencional de representação (Vorstellung) ainda permanece referida a uma imagem original. Mas o fato de a representação ser uma imagem, e não o original, proporciona uma autonomia da própria imagem em sua relação com o original. Ou seja, localiza-se, em termos representativos, no próprio objeto, seja original ou não. Tendo em vista tal entendimento, Gadamer recupera uma noção mais básica de representação (pensada como Darstellung), na qual a própria imagem é pensada de modo ontológico, enquanto "emanação do original" (GADAMER, 2004, p. 132). Desse modo, a relação entre original e cópia é repensada enquanto representação 6 (Darstellung), enfatizando assim o sentido ontológico reivindicado pela hermenêutica filosófica.

Tal discussão, acerca da representação como Vorstellung e Darstellung, aparece como o pano de fundo para compreender a própria experiência hermenêutica da arte e arquitetura, em termos representativos. Mesmo não aprofundando tal debate neste momento, é importante afirmar que tal estrutura representativa impõe-se como uma descrição da experiência da própria obra, recuperando assim um sentido outrora sedimentado e esquecido.

Ao transcender o conceito moderno de representação (enquanto Vorstellung), marcado pelo esquema no qual está em jogo a relação

\footnotetext{
6 Optamos por manter o termo representação, pois o próprio Gadamer o utiliza, sustentando seu sentido original na atividade de representação jurídica. Cf. GADAMER, H. G. Truth and Method. New York: Continuum, 2004. p. 142.
} 
de distanciamento entre um sujeito conhecedor e um objeto a ser conhecido, Gadamer reconsidera o conceito de representação em termos ontológicos (ou seja, como Darstellung), à medida que recupera um elemento próprio e anterior da relação sujeito e objeto, em grande medida herdando tal ponto da fenomenologia de Husserl, repensando uma estrutura na qual tanto o sujeito quanto o objeto são sempre em relação e também atravessados pelo próprio mundo compartilhado entre sujeito e obra, possibilitando, assim, reconsiderar uma relação na qual tanto sujeito quanto obra são constituídos e atravessados por uma relação básica com o mundo prático da vida. Há, portanto, uma relação essencialmente constitutiva entre sujeito e objeto artístico, não mais pensados como polos destacados objetivamente.

Em termos miméticos, segundo John Sallis, Gadamer faz uma "reabilitação da mímesis, que não significa apenas o sentido da imitação da cópia, mas como uma apresentação (Darstellung)" (FIGAL, 2007, p. 53). Ao identificar a noção gadameriana de representação como uma maneira de reformular a mimesis, Sallis observa que a formulação de Gadamer não quer ir além da representação, mas, permanecendo nela, inaugura novas e renovadas possibilidades de esclarecer o evento da compreensão.

Assim, o caráter ontológico da representação identificado por Gadamer, ao superar o esquema "original x cópia", compreende a representação nos termos de uma "transformação radical". Em outras palavras, a representação da obra de arte acontece quando algo mais do que a adequação ou harmonia com algo familiar ocorre na relação entre sujeito intérprete e obra. Sobre isso, Gottfried Boehm explica que "o prefixo re em representação significa intensificação. Essa intensificação acrescenta algo mais à existência do representado" (BOEHM, 2007, p. 17).

Segundo Gadamer, a imagem, como evento ontológico, não poderia ser concebida apenas como um objeto a ser apreendido por uma consciência estética, mas entendida em sua "fenomenalidade", inserida no horizonte imanente da vida prática. Nas palavras de Gadamer, "o caráter original da imagem é, antes, um momento essencial que encontra seu fundamento no caráter representativo da arte. [...] A imagem guarda uma relação indissolúvel com o seu mundo" (GADAMER, 2004, p. 144, grifo nosso).

\section{O ocasional e o decorativo como fontes da experiência da arquitetura}

Mesmo considerando que as obras de arte não se limitam a representar nada além do original, no sentido clássico de representação (Vorstellung), Gadamer afirma que elas ainda têm algo a dizer, o que significa afirmar seu valor ontológico (do ponto de vista da Darstellung), compreendido como a impossibilidade de dissociar as obras de arte do mundo histórico e prático no qual estão desde sempre inseridas. Em outras palavras, as obras de arte têm em si uma espécie de temporalidade e espacialidade resistente, que as ligam intimamente aos seus mundos.

Na perspectiva de Gadamer, a relação entre a temporalidade da obra de arte e a temporalidade externa revela o seu caráter de ocasionalidade. Focalizando na valência ontológica da imagem, essa noção é o "momento de sua chegada à representação, que faz com que sua experiência de sentido tenha maior determinação" (GADAMER, 2004, p. 139). Sendo assim, o sentido da obra de arte continua sendo determinado desde o momento em que foi criada até seu desaparecimento. É como se a própria obra levasse nela o seu sentido temporal e histórico próprio, mesmo que seja exposta em um museu distante de seu lugar original. Neste sentido, a estrutura da obra de arte é ocasional e o momento de sua performance revela o seu sentido mais próprio; em outros termos, a obra possui uma temporalidade ocasional própria.

De modo mais detalhado, a consideração do ocasional está sujeita a um questionamento ontológico do sentido da obra em sua performance, sempre referente ao seu momento histórico de criação, mas ao mesmo tempo não se limitando ao mesmo. As análises temporais ou históricas das obras revelam certos sentidos que não limitam a própria performance das obras, mas, ao contrário, a potencializa. 
Do ponto de vista do espaço, Gadamer considera o caráter decorativo da representação artística. A reabilitação desse aspecto, anteriormente negligenciado pela consciência estética moderna, constitui um retorno ao âmbito ao qual pertence uma obra de arte. A recuperação que Gadamer realiza da dimensão decorativa indica uma reafirmação de outro aspecto essencial da obra de arte, indicando assim sua conexão o sítio vital da própria obra.

É nesse contexto que as obras arquitetônicas, enquanto experiência ocasional e decorativa, podem ser pensadas ontologicamente, já que, enquanto obras estão estruturalmente vinculadas a um tempo e a um lugar. Tais caracteristicas, valorizadas por Gadamer como elementos hermenêuticos fundamentais, permitem-nos repensara própria relação com as obras de arte em geral, à medida que encontram na arquitetura um abrigo. Por essa razão, segundo Weinsheimer, "a arquitetura é uma arte totalmente compreensiva (omnicompreensive art) que absorve todas as outras a si e as reúne nela mesma" (WEINSHEIMER, 1985, p. 126).

Assim, as características ocasional e decorativo, tomadas de modo hermenêutico-ontológico, contribuem decisivamente para a compreensão da experiência da arte e, por conseguinte, da arquitetura como uma experiência de sentido histórica e situada. Deste modo, Gadamer convida-nos a repensar a arquitetura e suas mais diversas formas de expressão para além da engenharia e do mercado, apontando-nos um caráter fundamental e abrangente, à medida que oferece um lugar não apenas para as artes em geral, mas para o próprio homem. É neste momento que podemos recordar a resposta de Gadamer a Herzog, pois a lembrança do assoalho da sala da casa de seus pais é, em grande medida, uma referência aos aspectos ocasional e decorativo. E ao mesmo tempo, remete à arquitetura uma estrutura representativa, própria das obras de arte, no qual a relação entre intérprete e obra é constitutiva e marcada por um atravessamento vital.

Desse modo, do ponto de vista da hermenêutica filosófica, a arquitetura adquire um caráter paradigmático pois, como obra, atrai tudo para si; e, ao mesmo tempo, remete todas as coisas para além de si, ao contexto vital mais amplo. Esse duplo movimento de atração e retorno à vida prática, comum e histórica é, na visão de Gadamer, a essência do caráter ontológico-hermenêutico da arquitetura. Em outras palavras, os aspectos ontológicos ocasional e decorativo não se referem apenas à composição dos edifícios, mas, antes, ao modo de ser próprio das obras arquitetônicas, sempre em relação com a vida efetiva. A essencial ocasional e decorativa das obras, consideradas por Gadamer monumentos arquitetônicos, realizam um movimento de atração e retração, acolhendo-nos e enviando-nos à vida prática, estruturando-se como um movimento de um jogo.

A ligação entre o monumento arquitetônico e o tempo histórico (ocasional) e o espaço vital (decorativo) indica ainda, na perspectiva de Gadamer, que é da natureza da obra uma relação ontologicamente com seu próprio mundo enquanto rede de referências de sentido presentes na mesma. É neste sentido, que tais noções remetem a uma experiência de mediação entre o artista, intérprete, público, estudiosos, entre outros, e o significado da obra no curso da história. Tal experiencia distancia-se da consideração da obra de arquitetura como um objeto a ser dissecado por um sujeito, mas, antes, inserido na mesma esfera de experiência vital compartilhada, localizada historicamente no horizonte da práxis da vida.

Nesse sentido, a especificidade exemplar da arquitetura está relacionada a dois aspectos hermenêuticos fundamentais: como primeiro aspecto, a arquitetura é habitualmente examinada por sua finalidade e pelo espaço que ocupa; ou seja, por sua função e espacialidade. Deste modo, desde a realização do projeto até a efetiva construção, a experiência da arquitetura perpassa não somente o trabalho do arquiteto e sua equipe, mas possibilita diversas outras experiências por diversos sujeitos, tais como estudantes de arquitetura, estetas, engenheiros, moradores, prestadores de serviço, entre outros, para além do término da construção, na utilização e localização no mundo histórico da vida; e se estende até mesmo em seu reaproveitamento, no caso de um prédio histórico renovado. 
Gadamer pensa a arquitetura nos termos de uma solução feliz, à medida que insere uma nova experiência de sentido no espaço onde foi construido, transformando a paisagem na qual se insere. Dito de outra forma, uma construção arquitetônica revela elementos hermenêuticos ao passo que constitui uma obra que permite relações diversas com os sujeitos e com sua paisagem. Nesse sentido, todo monumento arquitetônico tem uma estrutura representativa própria, tal como Gadamer defende para a relação ontológica com as obras de arte.

Como segundo aspecto, Gadamer afirma encontrar na natureza da arquitetura algo além da solução para uma tarefa especifica, originalmente ligada aos elementos próprios da atividade do arquiteto. É próprio da arquitetura sustentar e remeter aos seus nexos vitais, mesmo quando sua função original é desfigurada. Nas palavras de Gadamer, "há algo [no monumento arquitetônico] aludindo ao original" (GADAMER, 2004, p. 149). Tal aspecto também compõe sua estrutura representativa básica, pois quando a função original é totalmente desfigurada, o edifício arquitetônico se torna, em alguma proporção, incompreensivel.

\section{Repercussões hermenêuticas no design arquitetônico}

A resposta de Gadamer - já relatada como Gadamer's floor - impactou de modo decisivo o trabalho de Herzog e Meuron: considerando inesperada e, em alguma medida, incomum uma resposta que remetesse a um elemento material que compõe as edificações em geral - o piso - , pensado a partir de sua composição artesanal de madeira e devidamente polido, os arquitetos compreenderam que, do ponto de vista de Gadamer, o sentido da arquitetura deve passar por uma experiência holistica que considera a arquitetura como uma linguagem a ser sempre ressignificada na própria obra e atividade de projetar e, por conseguinte, para além disso. Ou seja, pensar hermeneuticamente a arquitetura e seu contexto (projeto, estética, design, função etc.) significa compreender o seu sentido próprio e situado, enquanto compõe um certo espaço, dotando-o de sentido e, simultane- amente, remetendo a novas possibilidades para além deste ambiente construido, ou seja, ligando a edificação à vida comunitária.

Nesse sentido, Herzog e Meuron estenderam a tematização gadameriana do piso da sala de jantar para um projeto importante que trabalhariam anos depois: a transformação da Central Elétrica Bankside, na cidade de Londres, na nova sede do museu Tate Modern, obra especialmente lembrada por seu piso de madeira corrida. Como o próprio Herzog relata-nos:

costumo pensar na história de Gadamer devido a sua noção do 'real'. O piso de Gadamer (Gadamer's floor) descreve um conceito de realidade que não existe mais - a base arquitetônica artesanal e tradicional perdeu-se há algum tempo - mas, o que torna essa superfície tão interessante é o seu potencial arquitetônico para hoje. Nesse sentido, o piso da Gadamer pode se tornar um emblema de uma estratégia de design muito poderosa, com ênfase na materialidade, gravidade e manutenção; e seu foco no piso como piso (HERZOG, 2001, p. 115).

A repercussão hermenêutica no design arquitetônico da Tate Modern, inspirada no piso da casa de Gadamer como material fundamental para uma edificação, possibilitou uma reflexão filosófica aos arquitetos acerca de um elemento básico de projetos de arquitetura e design: o sentido do material. Ou seja, a compreensão da especificidade de um material enquanto parte que compõe uma obra e, por conseguinte, remete ao todo de uma obra no contexto da vida social surge como uma experiência hermenêutica. Em uma perspectiva gadameriana, é o que podemos experimentar no projeto de conversão da central elétrica em museu, mesmo com a finalização da obra, ou seja, quando o projeto se torna obra. Assim, a atenção aos materiais, enquanto elementos fundamentais que compõem de modo decisivo a própria significação do design de uma edificação, à medida que, reunidos naquela obra, mesmo que ainda em projeto, remetem para além dela, ou seja, para a vida em comum com os outros. Afirma Herzog:

Diferentemente do parquet de Gadamer, o piso da Tate Modern é um produto intelectual e não artesanal. Não estávamos interessados em revitalizar nostalgicamente métodos antigos da 
produção tradicional, mas estávamos interessados no resultado físico, na realidade física da arquitetura tradicional. [...] Desta forma, o piso da Tate Modern se tornou um protótipo para nossa abordagem conceitual e estratégica de uma arquitetura; uma abordagem que muitas vezes é mascarada com o traje tradicional de elementos arquitetônicos que todos parecem ter visto de alguma forma antes - confortáveis e familiares (HERZOG, 2001, p. 115).

Em um primeiro momento, o piso da sala de Gadamer aparece como um produto artesanal, tradicional às casas alemãs de uma certa época. Contudo, à medida que é tematizado filosoficamente por Gadamer, torna-se também um elemento intelectual, pois se transforma em uma noção a ser discutida e ressignificada tanto filosoficamente quanto arquitetonicamente. Por isso, ao argumentar acerca do que está em jogo naquele elemento material e artesanal - o piso - Gadamer transmite novas possibilidades de sentido não somente para o material elencado, mas para a própria atividade da arquitetura e urbanismo e, por conseguinte, para a área de design. Ao tratar de materiais essenciais a construções e/ ou composições de espaços, busca-se trazer novos sentidos, assim como novas possibilidades de vida que, por conseguinte, remete ao mundo comum e familiar, onde a vida efetiva acontece.

\section{Considerações finais}

Na perspectiva de Gadamer, a atividade arquitetônica, compreendida tanto como teoria e prática de projeto quanto através das mais diversas obras de arte arquitetônicas construidas ao longo da história humana, possui um caráter hermenêutico próprio, que afeta tanto aqueles que projetam e constroem quanto aqueles que observam ou frequentam as obras edificadas. Deste modo, repensar a arquitetura como uma experiência interpretativo-filosófica significa ir além da diferenciação estética, isto é, afirmar o caráter de não diferenciação constitutiva de cada projeto ou obra, pensando as múltiplas significações, advindas dos materiais, formas e funções da composição, sempre em relação com o contexto mais amplo da vida em comum.

São as obras arquitetônicas que nos reúnem e, ao mesmo tempo, remetem-nos à vida prática. Em grande medida, tais obras realizam, desde sua concepção, mediações de sentido, especialmente na relação entre presente e passado, tornando tais obras espaços de reunião e, ao mesmo tempo, de compreensão da vida social. É o caso, por exemplo, de um edifício histórico: tanto nos remete a um passado, através de seus materiais, formas, funções, entre outros elementos e, ao mesmo tempo, é passivel de ressignificação, à medida que se pode rever o próprio projeto devido a necessidades quaisquer, fazendo sua recomposição com novos materiais, funções, formas, trazendo à luz novos sentidos.

Deste modo, ao pensar a arquitetura como configuradora de espaços, Gadamer prevê um sentido hermenêutico à própria atividade do arquiteto que, por conseguinte, engloba necessariamente a comunidade em torno da obra. Ao passo que lida com uma edificação, o arquiteto estará sempre referido à efetividade da vida atual, tornando sua atividade um âmbito privilegiado no qual novos sentidos acontecem, especialmente nos desdobramentos da relação entre indivíduos, projeto e edificação. Na efetividade da obra construida, todos que se relacionam com a obra arquitetônica, desde o projeto até sua efetiva ocupação, podem ser radicalmente transformados e remetidos à imanência da vida prática em comum na experiência da própria edificação.

\section{Referências}

AKIN, Ömer; WEINEL, Eleanor F. (ed.). Representation and Architecture. Maryland: Information Dynamics, 1982.

BARNARD, Malcolm. Gadamer, Hans-Georg (19002002). In: BHAGAT, D.; KETTLEY, S.; O'BRIEN, S.; RAIZMAN, D.; WILLIS, A-M (ed.) Bloomsbury Encyclopedia of Design. Londres: Bloomsbury Academic, 2016. p. 63-64. https://doi.org/10.5040/97814725.96161-BED-G002.

BOEHM, Gottfried. Representation, presentation, presence: tracing the homo Pictor. In: ALEXANDER, Jeffrey C.; BARTMANSKI, Dominik; GIESEN, Bernhard (ed.) Iconic Power: materiality and meaning in social life. Basingstoke: Palgrave Macmillan, 2007. p. 15-23. https://doi. org/10.1057/9781137012869_2.

BRANDÃO, Carlos Antônio Leite. Hermenêutica e Verdade na Obra de Arquitetura. Kriterion. Belo Horizonte, n. 101, p. 7-19, jun. 2000. 
BRANDÃO, Carlos Antônio Leite. Introdução à hermenêutica da arte e da arquitetura. Topós: Revista de Arquitetura e Urbanismo. Belo Horizonte, v. 1, n. 1, p. 113-123, 1999.

BRUDERLIN, Markus (ed.). Ornament and Abstraction: the dialogue between non-western, modern and contemporary art. Basel: Foundation Beyeler, 2001.

CARDOSO, Rafael. Design para um mundo complexo. São Paulo: Editora UBU, 2016.

FARRELY, Lorraine. The Fundamentals of Architecture. Lousanne: Ava Book, 2007.

FEHER, István M. Kunst, Hermeneutic, Philosophie: das Denken Hans-Georg Gadamers in Zusammenhang des 20 Jahrhunderts. Heidelberg, Universitätsverlag, 2003.

FIGAL, Günter (org.). Hans-Georg Gadamer: Wahrheit und Methode. Berlin: Akademie Verlag, 2007. https:// doi.org/10.1524/9783050050195.

GADAMER, H-G. Truth and Method. Transl. Joel Weisheimer. New York: Continuum, 2004.

GRONDIN, J. Hans-Georg Gadamer: a biography. New Haven: Yale University Press, 2003. https://doi. org/10.1007/978-3-476-98618-4_49.

GRONDIN, Jean. Gadamer's Aesthetics: the overcoming of aesthetic consciousness and the hermeneutical truth of art. In: KELLY, M. (org.). Encyclopedia of Aesthetics. Oxford: Oxford University Press, 1998. v. 2, p. 276-271.

HERZOG, Jacques. Thinking of Gadamer's floor. In: DAVIDSON, Cynthia C. (ed.). Anything. New York: Anyone Corporation; Cambridge, MA: The MIT Press, 2001. p. 114-119.

KIDDER, Paul. Gadamer for Architects. New York: Routledge, 2013. https://doi.org/10.4324/9780203073223.

MITROVIC, Branko. Philosophy for Architects. New York: Princeton Architectural Press, 2011.

UDOVICKI-SELB, Danilo. Between Formalism and Deconstruction: Hans-Georg Gadamer's hermeneutics and the aesthetics of reception. In: POLLAK, Martha (ed.). The Education of the Architect: historiography, urbanism, and growth of architectural knowledge. Cambridge: The MIT Press, 1997. p. 239-266.

VESELY, Dalibor. Architecture and the conflict of representation. Annals of the Architecture Association School of Architecture - AA FILES, London, n. 8, p. 21-38, 1985.

VESELY, Dalibor. Architecture in the age of divided representation: the question of creativity in the shadow of production. Cambridge, MA: The MIT Press, 2004.

WEINSHEIMER, Joel. Gadamer's Hermeneutics: A Reading of Truth and Method. New Haven: Yale University Press, 1985.

WISCHKE, Mirko. Hans-Georg Gadamer. In: SEPP, Hans Rainer; EMBREE, Lester. (org.). Handbook of Phenomenological Aesthetics. Dordrecht: Springer, 2010, v. 59. p. 123-125.

\section{Gustavo Silvano Batista}

Doutor em Filosofia pela Pontifícia Universidade Católica do Rio de Janeiro (PUC-Rio)/Universidade de Copenhague, no Rio de Janeiro, RJ, Brasil. Professor da Universidade Federal do Piaui (UFPI), em Teresina, PI, Brasil.

\section{Endereço para correspondência}

Gustavo Silvano Batista

Universidade Federal do Piauí

Departamento de Filosofia - Centro de Ciências Humanas e Letras

Campus Ministro Petrônio Portela

Avenida Universitária, $\mathrm{s} / \mathrm{n}$

Ininga, 64049550

Teresina, PI, Brasil 